\title{
A Taxonomic Review of the Genera Kitasatosporia and Streptoverticillium by Analysis of Ribosomal Protein AT-L30
}

\author{
$\mathrm{KOZO} \mathrm{OCHI}^{1 *}$ AND HIDENORI HIRANUMA ${ }^{2}$ \\ National Food Research Institute, 2-1-2 Kannondai, Tsukuba, Ibaraki 305, ${ }^{1}$ and Applied Biosystems Japan, \\ 3-3-6 Minamisuna, Koto-ku, Tokyo 136, Japan
}

\begin{abstract}
An analysis of the ribosomal AT-L30 proteins from 42 strains of 35 species belonging to the genera Streptomyces, Streptoverticillium, and Kitasatosporia and related genera revealed that all of the members of the genera Streptoverticillium and Kitasatosporia examined had the same sequence as Streptomyces exfoliatus or a highly homologous sequence and exhibited high levels of relatedness to Streptomyces lavendulae. These results strongly support the previous suggestion of Witt and Stackebrandt (D. Witt and E. Stackebrandt, Syst. Appl. Microbiol. 13:361-371, 1990) and Wellington et al. (E. M. H. Wellington, E. Stackebrandt, D. Sanders, J. Wolstrup, and N. O. G. Jorgensen, Int. J. Syst. Bacteriol. 42:156-160, 1992) that the genera Streptoverticillium and Kitasatosporia should be united with the genus Streptomyces on the basis of $16 \mathrm{~S}$ rRNA data.
\end{abstract}

Among the actinomycetes, the family Streptomycetaceae originally contained the genera Streptoverticillium, Actinopycnidium, Microellobosporium, Chainia, Kitasatoa, and Elytrosporangium. However, all of these genera except the genus Streptoverticillium were reclassified by Goodfellow et al. (5-8) because of their phenetic, chemotaxonomic, and genomic similarities $(2,14,15,34,35)$. The only genus of the family not united with the genus Streptomyces was the genus Streptoverticillium, probably because the members of this genus have significant morphological characteristics; namely, they form aerial mycelia which consist of long, straight filaments bearing whorls consisting of three to six branches (16). A total of 24 species were included in this genus in Bergey's Manual of Systematic Bacteriology (16). The genus Kitasatosporia was proposed by Omura et al. $(27,32)$ in 1982 for newly isolated strains whose cell walls contained similar amounts of the LL and meso isomers of diaminopimelic acid, as well as glycine and galactose; only three species (Kitasatosporia setae, Kitasatosporia griseola, and Kitasatosporia phosalacinea) are listed in this genus in Bergey's Manual of Systematic Bacteriology (26). Kitasatosporia cystarginea is a recently described species which was originally isolated by Kusakabe and Isono (12). Although the members of the genus Kitasatosporia are similar to members of Streptomyces spp. in both morphology and physiology, cultivation in liquid media results in production of spore-like cells which contain LL-diaminopimelic acid, whereas the mycelium contains meso-diaminopimelic acid (31). Most Streptomyces species do not produce spores in liquid cultures; the only exception is Streptomyces griseus, which can produce submerged spores (3). Members of the genus Kitasatosporia are also differentiated from Streptomyces species by the presence of galactose in whole-cell hydrolysates (27).

The taxonomic status of the genera Streptoverticillium and Kitasatosporia remained uncertain until members of these taxa were subjected to a phylogenetic analysis. The results of a recent study in which partial 16S rRNA sequences were compared indicated that all of the Streptomyces and Streptoverticillium strains examined were members of one of several phylogenetically defined lines of descent in the order Actinomycetales (36). These organisms did not cluster according to their placement in different genera, and certain members of the genus Streptomyces were more closely related to strepto-

\footnotetext{
* Corresponding author. Phone: 0298-38-8125. Fax: 0298-38-7996.
}

verticillia than to other members of their own genus. On the basis of high levels of phylogenetic similarity, in addition to phenetic similarities (35), Witt and Stackebrandt (36) proposed that the genera Streptoverticillium and Streptomyces should be combined. Likewise, more recently, Wellington et al. (33) proposed to that the genus Kitasatosporia should be synonymous with the genus Streptomyces on the basis of phenetic analysis data and on the basis of homology of stretches of $16 \mathrm{~S}$ rRNA. Nakagaito et al. proposed that $K$. cystarginea should be transferred to the genus Streptomyces on the basis of physiological, chemotaxonomic, and DNA-DNA hybridization data (17). (In this paper, for convenience, we use the names Streptoverticillium and Kitasatosporia instead of the unified name Streptomyces.)

Ribosomes and their components have provided an excellent way to study the evolution of organisms, since they are essential components of all cells. During the last few years, we have demonstrated that analysis of ribosomal AT-L30 proteins (homologous to Escherichia coli L30 protein) can be used for classification of actinomycetes at the genus level (19-25). The aim of this study was to investigate the taxonomic structure of the streptomycetes.

\section{MATERIALS AND METHODS}

Bacterial strains. The strains used in this study are listed in Table 1. Almost all of the strains were type strains that were obtained from the following sources: Japan Collection of Microorganisms, Saitama, Japan; Institute of Fermentsion, Yodogawa-ku, Osaka, Japan; Fermentation Research Institute, Tsukuba, Japan; Kitasato Institute, Minato-ku, Tokyo, Japan; Institute of Microbial Chemistry, Shinagawa-ku, Tokyo, Japan; American Type Culture Collection, Rockville, Md; and John Innes Institute, Norwich, England. The strains were grown in soluble starch-Polypeptone-yeast extract medium at $30^{\circ} \mathrm{C}(23)$.

Preparation of total ribosomal proteins and two-dimensional PAGE. After cultivation for 15 to $20 \mathrm{~h}$ (to midexponential phase), the cells were collected, washed, and then disrupted by sonication for 3 to $5 \mathrm{~min}$. The $70 \mathrm{~S}$ ribosomes were pelleted by centrifugation at $110,000 \times g$ for $4 \mathrm{~h}$. Ribosomal proteins were prepared from $70 \mathrm{~S}$ ribosomes by extraction with acetic acid, as described previously (18), by using the method of Hardy et al. (9). The total ribosomal protein samples obtained in this way contained 20 to $30 \mathrm{mg}$ of protein per $\mathrm{ml}$. 

1 5 10 15
20
1) Ala-Arg-Leu-Lys-I e-Thr-Gln-Thr-Lys-Ser Tyr Il e-Gly Ser-Lys-Gln-Asn - ? - ? -Asp Thr-Leu
2) Ala-Arg-Leu-Lys-Ile-Thr-Gin-Thr-Lys-Ser Tyr II e-Gly Ser-Lys-Gln-Asn - ? - ? -Asp
3) Ala-Arg-Leu-Lys-Il e-Thr-Gln-Thr-Lys-Ser Tyr II e-Gly Ser-Lys-Gln-Asn- ? - ? -Asp-Thr LLeu
4) Ala-Arg-Leu-Lys-Ile-Thr-Gln-Thr-Lys-Ser Tyr Il e-Gly Ser-Lys-Gln-Asn- ? - ? -Asp
5) Ala-Arg-Leu-Lys-Ile-Thr-Gln-Thr-Lys-Ser Tyr Il e-Gl y Ser-Lys-Gln-Asn- ? - ? -Asp
6) Ala-Arg-Leu-Lys-Ile-Thr-Gln-Thr-Lys-Ser Tyr Il e-Gly Ser-Lys-Gln-Asn- ? - ? -Asp
7) Ala -Arg-Leu -Lys-I1 e-Thr-G1n-Thr-Lys-Ser Tyr Il e-G1 y fSer Lys-G1n-Asn- ? - ? -Asp Thr LLeu
8) Ala-Arg-Leu-Lys-Val-Thr-Gln-Thr-Lys-Ser Tyr-Il e-Gly Ser-Lys-Gin-Asn- ? - ? -Asp Thr-Leu
9) Ala-Arg-Leu-Lys-Val-Thr -G1n-Thr-Lys-Ser Tyr-Ile-Gly Ser-Lys-G1n-Asn - ? - ? -Asp
10) Ala-Gln-Leu-Lys-I1 e-Thr-Gln-Val-Lys-Ser Tyr II e-Gly Ser Lys-Gln-Asn- ? - ? -Asp Thr LLeu
11) Ala-Gln-Leu-Lys-Ile-Thr-GIn-Val-Lys-Ser Tyr Il e-Gly -Ser-Lys-Gln-Asn- ? - ? -Asp
12) Ala-Gln-Leu-Lys-Il e-Thr-Gln-Val-Lys-Ser Tyr Il e-Gly Ser-Lys-Gln-Asn- ? - ? -Asp
13) Ala-GIn-Leu-Lys-Ile-Thr-Gln-Val-Lys-Ser Tyr Il e-GIy Ser-Lys-GIn-Asn- ? - ? -Asp Thr -Leu- ? -Ser-Leu
1.4) Ala-Gln-Leu-Lys-Il e-Thr-Gln-Thr-Lys-Ser Tyr Il e-G1 y-Ser-Lys-Gln-Asn- ? - ? -Asp
15) Ala-GIn-Leu-Lys-Ile-Thr-Gln-Thr-Lys-Ser Tyr Il e-Gl y Ser-Lys-Gln-Asn- ? - ? -Asp
16) Ala-Gln-Leu Arg I1 e-Thr-Gln-Val-Lys-Ser TyrfIle-Gly Ser Lys-Gln-Asn- ? - ? -Asp-Thr Leu - ? -Ser-Leu
17) Ala-Gln-Leu Arg II e-Thr-Gln-Val-Lys-Ser Tyr Il e-Giy Ser Lys-Gin-Asn-? - ? -Asp Thr LLeu- ? -Ser-Leu
18) Ala-Gln-Leu Arg Il e-Thr-GIn-Val-Lys-Ser Tyr II e-Gl y Ser-Lys-Gln-Asn- ? - ? -Asp
19) Ala-Arg-Leu-Lys-Ile-Thr-Gln-Thr-Lys-Ser Tyr IIle-Gl y Ser-Lys-Gln-Asn- ? - ? -Asp Thr LLeu- ? -Ser-Leu
20) Ala-Arg-Leu-Lys-Ile-Thr-Gln-Thr-Lys-Ser Tyr Ile-Gl y Ser Lys-G1n-Asn- ? - ? -Asp Thr LLeu - ? -Ser-Leu
21) Ala-Gln-Leu-Lys-I1 e-Thr-G1n-Thr-Lys-Ser Tyr Ile-G1 y Ser-Lys-G1n-Asn- ? - ? -Asp-Thr Leu
22) Met-Arg-Il e-Lys-II e-Thr-GIn-Thr-Lys-Ser TyrfI le-Gly Ser-Lys-GIn-Asn- ? - ? -Asp Thr Leu- ? -Ser-Leu
23) Ala-Lys-Ile-Lys-Ile-Thr-GIn-Thr- ? -Ser Lys I I e-Gly-Gly-Lys-Gln
24) Ala-Lys-Leu-Lys-Ile-Thr-GIn-Thr-Lys-Ser Ser II e-Gly- ? -GIn-Gln- ? - ? - ? -Asp
25) Ala- ? -Leu-Lys-I le-Thr-Gln-Val-Arg-Ser Lys II le-Gl y-Gly-Lys-G1n-Asn-G1n- ? -Asp
26) Ala-Gln-Leu-Lys-Val-Thr-Gln-Val-Lys-Ser Ser Il e-Gly-Thr-Lys-Gln-Asn- ? - ? -Asp
27) Ala-Gln-Leu-Lys-I le-Thr-Gln-Thr-Lys-Ala Val I I e-Asn
28) Ala-Arg-Leu-Lys-Ile-Thr-Gln-Val-Arg-Ser Lys I1 e-Gly-Gly-Lys-Gln-Asn-Gln- ? -Asp-Ser-Leu- ? - ? -Leu
29) Ala-Gln-Leu-Lys-Val-Gln-Gln-Lys-Lys-Gl y LLeu Val-Gly-Leu-Lys-Gln-Asn-Gln- ? -Asp
30) Ala-Arg-Leu-Lys-Val-Thr-Gln-Ile-Arg-SerfGlyfIle-G1y- ? -Lys-G1n-Asn-Gln- ? -Asp- ? -Leu
31) Ala-Glu-Leu-Lys-Ile-Thr-Gln- ? -Lys-Ser Thr Ile-Gly-Ala-Lys- ? -Asn-Gln- ? -Asp- ? -Leu
32) Ala-Arg-Leu-Lys-Val-Thr-Gln-Val-Arg-Ser GlufIl e-Gly-Thr-Lys-Lys-Asn-Gln- ? -Asp-Ser-Leu
33) Ala-Asp-Leu-Lys-Val-Thr-Gln-Il e-Lys-Ser-ThrfIl e-Gl y-Ala-Lys-Ala-Asn-G1n-Lys-Asp-Ser-Leu

FIG. 1. Primary structures of N termini of AT-L30 proteins from various species of the genus Streptomyces and related genera. The data for Actinomadura malachitica and Microbispora amethystogenes are from reference 21, and the data for Streptosporangium roseum and Streptosporangium viridogriseum subsp. kofuense are from reference 22 . Question marks indicate amino acids that were not determined. The amino acids that characterize each genus are indicated by boxes. Line 1, Streptomyces griseus JCM4644 ${ }^{\mathrm{T}}$ (T = type strain); line 2, Streptomyces griseus IFO 13189; line 3, Streptomyces lavendulae IFO $12789^{\mathrm{T}}$; line 4, Streptomyces lavendulae MA406-A-1; line 5, Streptomyces lavenulae subsp. grasserius JCM $4056^{\mathrm{T}}$; line 6, Streptomyces lavendulae subsp. fuscus JCM 5025 $5^{\mathrm{T}}$; line 7, Streptomyces hygroscopicus IFO $13472^{\mathrm{T}}$; line 8, Streptomyces exfoliatus JCM $4366^{\mathrm{T}}$; line 9, Streptomyces venezuelae IFO $13096^{\mathrm{T}}$; line 10, Streptomyces coelicolor A3(2); line 11, Streptomyces lividans 66; line 12, Streptomyces violaceus IFO $13103^{\mathrm{T}}$; line 13, Streptomyces parvulus ATCC $12434^{\mathrm{T}}$; line 14 , Streptomyces antibioticus JCM $4620^{\mathrm{T}}$; line 15 , Streptomyces antibioticus ATCC 
TABLE 1. Strains used in this study

\begin{tabular}{|c|c|c|c|}
\hline Species or subspecies & Strain & Cluster group ${ }^{u}$ & Sources $^{b}$ \\
\hline Streptomyces antibioticus & $\operatorname{JCM} 4620^{\mathrm{T}}\left(=\text { ATCC } 23879^{\mathrm{T}}\right)^{\mathrm{C}}$ & A31 & $\mathrm{JCM}$ \\
\hline Streptomyces antibioticus & ATCC 14888 & & ATCC \\
\hline Streptomyces coelicolor & $\mathrm{A} 3(2)^{d}$ & & JII \\
\hline Streptomyces exfoliatus & $\operatorname{JCM} 4366^{\mathrm{T}}\left(=\right.$ ATCC $\left.19750^{\mathrm{T}}\right)$ & A5 & $\mathrm{JCM}$ \\
\hline Streptomyces griseoflavus & JCM $4479^{\mathrm{T}}\left(=\right.$ ATCC $\left.25456^{\mathrm{T}}\right)$ & A37 & JCM \\
\hline Streptomyces griseoflavus & JCM 4040 & & $\mathrm{JCM}$ \\
\hline Streptomyces griseoflavus & JCM 4142 (= ATCC 12269) & & JCM \\
\hline Streptomyces griseoflavus & JCM 4878 & & $\mathrm{JCM}$ \\
\hline Streptomyces griseoflavus & FERM 1805 & & FERM \\
\hline Streptomyces griseus & $\operatorname{JCM~} 4644^{\mathrm{T}}\left(=\operatorname{ATCC} 23921^{\mathrm{T}}\right)$ & A1 & JCM \\
\hline Streptomyces griseus & IFO 13189 & & IFO \\
\hline Streptomyces hirsutus & $\operatorname{JCM} 4191^{\mathrm{T}}\left(=\operatorname{ATCC} 19773^{\mathrm{T}}\right)$ & A37 & JCM \\
\hline Streptomyces hygroscopicus & IFO $13472^{\mathrm{T}}\left(=\right.$ ATCC $\left.27438^{\mathrm{T}}\right)$ & A32 & IFO \\
\hline Streptomyces lavendulae & IFO $12789^{\mathrm{T}}\left(=\operatorname{ATCC} 19777^{\mathrm{T}}\right)$ & F61 & IFO \\
\hline Streptomyces lavendulae & MA406-A-1 & & IMC \\
\hline Streptomyces lavendulae subsp. grasserius & $\mathrm{JCM} 4056^{\mathrm{T}}\left(=\mathrm{ATCC} 15875^{\mathrm{T}}\right)$ & $\mathrm{ND}^{e}$ & JCM \\
\hline Streptomyces lavendulae subsp. fuscus & $\mathrm{JCM} 5025^{\mathrm{T}}$ & ND & $\mathrm{JCM}$ \\
\hline Streptomyces lividans & 66 & & JII \\
\hline Streptomyces parvulus & ATCC $12434^{\mathrm{T}}$ & $\mathrm{A} 12$ & ATCC \\
\hline Streptomyces prasinus & $\operatorname{JCM} 4192^{\mathrm{T}}\left(=\right.$ ATCC $\left.19800^{\mathrm{T}}\right)$ & A37 & $\mathrm{JCM}$ \\
\hline Streptomyces venezuelae & IFO $13096^{\mathrm{T}}\left(=\right.$ ATCC $\left.25508^{\mathrm{T}}\right)$ & A6 & IFO \\
\hline Streptomyces violaceus & IFO $13103^{\mathrm{T}}\left(=\operatorname{ATCC} 25515^{\mathrm{T}}\right)$ & A6 & IFO \\
\hline Streptoverticillium baldaccii (Streptomyces baldaccii) ${ }^{f}$ & $\operatorname{JCM} 4272^{\mathrm{T}}\left(=\operatorname{ATCC} 23654^{\mathrm{T}}\right)$ & ND & $\mathrm{JCM}$ \\
\hline $\begin{array}{l}\text { Streptoverticillium cinnamoneum subsp. cinnamoneum } \\
\text { (Streptomyces cinnamoneus) }\end{array}$ & $\operatorname{JCM} 4152^{\mathrm{T}}\left(=\operatorname{ATCC} 23897^{\mathrm{T}}\right)$ & F55 & $\mathrm{JCM}$ \\
\hline $\begin{array}{l}\text { Streptoverticillium griseocarneum (Streptomyces } \\
\text { griseocarneus) }\end{array}$ & $\mathrm{JCM} 4095^{\mathrm{T}}\left(=\mathrm{ATCC} 19763^{\mathrm{T}}\right)$ & F55 & $\mathrm{JCM}$ \\
\hline Streptoverticillium orinoci (Streptomyces orinoci) & $\operatorname{JCM} 4807^{\mathrm{T}}\left(=\operatorname{ATCC} 23202^{\mathrm{T}}\right)$ & F58 & $\mathrm{JCM}$ \\
\hline Kitasatosporia cystarginea (Streptomyces cystargineus) & $\operatorname{JCM} 7356^{\mathrm{T}}\left(=\operatorname{ATCC} 49931^{\mathrm{T}}\right)$ & & KI \\
\hline Kitasatosporia griseola (Streptomyces griseolosporeus) & KA $341^{\mathrm{T}}\left(=\operatorname{JCM} 3339^{\mathrm{T}}=\operatorname{DSM} 43859^{\mathrm{T}}\right)$ & & KI \\
\hline Kitasatosporia papulosa (Streptomyces sp.) & KA $655^{\mathrm{T}}\left(=\operatorname{JCM} 7250^{\mathrm{T}}=\operatorname{ATCC} 49231^{\mathrm{T}}\right)$ & & KI \\
\hline Kitasatosporia Phosalacinea (Streptomyces phosalacineus) & KA $338^{\mathrm{T}}\left(=\text { JCM } 3340^{\mathrm{T}}=\text { DSM } 43860^{\mathrm{T}}\right)^{\prime}$ & & KI \\
\hline Kitasatosporia setae (Streptomyces setae) & $\operatorname{JCM} 3304^{\mathrm{T}}\left(=\operatorname{ATCC} 33774^{\mathrm{T}}\right)$ & & KI \\
\hline Actinomadura malachitica & JCM $3297^{\mathrm{T}}\left(=\right.$ ATCC $\left.27888^{\mathrm{T}}\right)$ & & JCM \\
\hline Actinoplanes phillipinensis & $\operatorname{JCM} 3001^{\mathrm{T}}\left(=\operatorname{ATCC} 12427^{\mathrm{T}}\right)$ & & $\mathrm{JCM}$ \\
\hline Dactylosporangium aurantiacum & IFO $12592^{\mathrm{T}}\left(=\right.$ ATCC $\left.23491^{\mathrm{T}}\right)$ & & IFO \\
\hline Microbispora amethystogenes & $\mathrm{JCM} 3021^{\mathrm{T}}$ & & $\mathrm{JCM}$ \\
\hline Micromonospora chalcea & $\operatorname{JCM} 3031^{\mathrm{T}}\left(=\operatorname{ATCC} 12452^{\mathrm{T}}\right)$ & & $\mathrm{JCM}$ \\
\hline Nocardia asteroides & $\operatorname{JCM} 3384^{\mathrm{T}}\left(=\right.$ ATCC $\left.19247^{\mathrm{T}}\right)$ & & JCM \\
\hline Nocardioides flavus & $\mathrm{JCM} 3334^{\mathrm{T}}$ & & $\mathrm{JCM}$ \\
\hline Nocardiopsis dassonvillei & IFO 13908 & & IFO \\
\hline Streptosporangium roseum & $\operatorname{JCM} 3005^{\mathrm{T}}\left(=\operatorname{ATCC} 12428^{\mathrm{T}}\right)$ & & JCM \\
\hline Streptosporangium viridogriseum subsp. kofuense & $\operatorname{JCM} 3157^{\mathrm{T}}\left(=\operatorname{ATCC} 27102^{\mathrm{T}}\right)$ & & JCM \\
\hline Thermomonospora chromogena & JCM $6244^{\mathrm{T}}$ & & $\mathrm{JCM}$ \\
\hline
\end{tabular}

${ }^{a}$ Cluster groups of Williams et al. (35).

${ }^{b}$ ATCC, American Type Culture Collection; FERM, Fermentation Research Institute; JCM, Japan Collection of Microorganisms; JII, John Innes Institute; IFO, Institute of Fermentation; IMC, Institute of Microbial Chemistry; KI, Kitasato Institute.

c $\mathbf{T}=$ type strain.

${ }^{d}$ This strain is a misclassified strain of Streptomyces violaceoruber.

ND, not determined.

${ }^{f}$ The names in parentheses are emended names.

Two-dimensional polyacrylamide gel electrophoresis (PAGE) by the method of Kaltschmidt and Wittmann (10) has been described in detail previously (18).

Determination of amino acid sequence. To prepare AT-L30 protein samples for amino acid sequence analysis, large amounts ( 7 to $10 \mathrm{mg}$ ) of total ribosomal proteins were applied to PAGE gels. After two-dimensional PAGE, the proteins were extracted from the gels by dry type electrophoresis with Sartoblot II-S (catalog no. SM 17556; Sartorius, Göttingen, Germany), as described below. Electrophoresis was carried out for $6 \mathrm{~h}$ at a constant current of $400 \mathrm{~mA}$ (initial voltage, $7 \mathrm{~V}$ ); the protein was extracted from each gel on a membrane

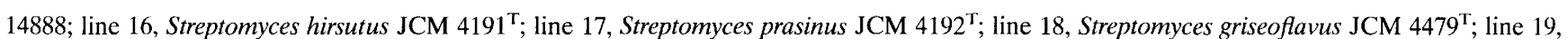
Streptomyces griseoflavus JCM 4040; line 20, Streptomyces griseoflavus FERM 1805; line 21, Streptomyces griseoflavus JCM 4878; line 22, Streptomyces griseoflavus JCM 4142; line 23, Nocardiopsis dassonvillei IFO 13908; line 24, Microbispora amethystogenes JCM 3021 ${ }^{\mathrm{T}}$; line 25 Streptosporangium roseum JCM $3005^{\mathrm{T}}$; line 26, Streptosporangium viridogriseum subsp. kofuense JCM $3157^{\mathrm{T}}$; line 27 , Actinomadura malachitica JCM $3297^{\mathrm{T}}$; line 28 , Thermomonospora chromogena $\mathrm{JCM} 6244^{\mathrm{T}}$; line 29 , Nocardioides flavus $\mathrm{JCM} 3334^{\mathrm{T}}$; line 30 , Actinoplanes phillipinensis JCM $3001^{\mathrm{T}}$; line 31, Dactylosporangium aurantiacum IFO 12592 ${ }^{\mathrm{T}}$; line 32, Micromonospora chalcea JCM 3031 ${ }^{\mathrm{T}}$; line 33 , Nocardia asteroides JCM 3384 ${ }^{\mathrm{T}}$. 
TABLE 2. SAS values for the amino acid sequences of AT-L30 proteins ${ }^{a}$

\begin{tabular}{|c|c|c|c|c|c|c|c|c|c|c|c|c|c|}
\hline \multirow[b]{2}{*}{ Strain } & \multicolumn{13}{|c|}{ SAS values $(\%)$} \\
\hline & 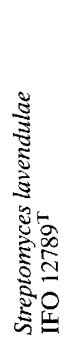 & 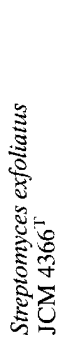 & 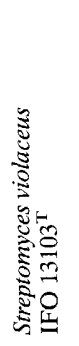 & 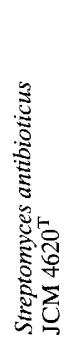 & 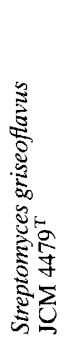 & 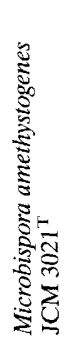 & 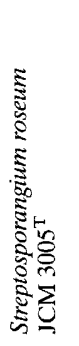 & 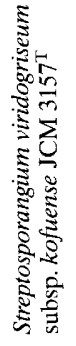 & 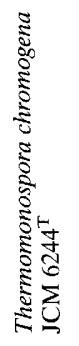 & 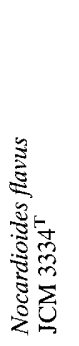 & 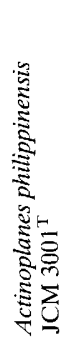 & 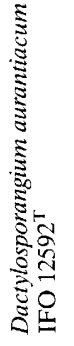 & 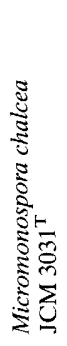 \\
\hline Streptomyces exfoliatus JCM $4366^{\mathrm{T}}$ & 94 & & & & & & & & & & & & \\
\hline Streptomyces violaceus IFO $13103^{\mathrm{T}}$ & 89 & 83 & & & & & & & & & & & \\
\hline Streptomyces antibioticus JCM $4620^{\mathrm{T}}$ & 94 & 89 & 94 & & & & & & & & & & \\
\hline Streptomyces griseoflavus JCM $4479^{T}$ & 83 & 78 & 94 & 89 & & & & & & & & & \\
\hline $\begin{array}{l}\text { Microbispora amethystogenes JCM } \\
3021^{\mathrm{T}}\end{array}$ & 81 & 75 & 75 & 81 & 69 & & & & & & & & \\
\hline Streptosporangium roseum $\mathrm{JCM} 3005^{\mathrm{T}}$ & 76 & 72 & 82 & 76 & 76 & 73 & & & & & & & \\
\hline $\begin{array}{l}\text { Streptosporangium viridogriseum subsp. } \\
\text { kofuense JCM } 3157^{\mathrm{T}}\end{array}$ & 72 & 78 & 83 & 78 & 78 & 75 & 76 & & & & & & \\
\hline $\begin{array}{l}\text { Thermomonospora chromogena JCM } \\
6244^{\mathrm{T}}\end{array}$ & 78 & 74 & 78 & 72 & 72 & 69 & 100 & 72 & & & & & \\
\hline Nocardioides flavus JCM $3334^{\mathrm{T}}$ & 56 & 63 & 61 & 61 & 56 & 50 & 56 & 67 & 53 & & & & \\
\hline Actinoplanes philippinensis JCM $3001^{\mathrm{T}}$ & 76 & 83 & 71 & 71 & 65 & 63 & 82 & 76 & 83 & 61 & & & \\
\hline $\begin{array}{l}\text { Dactylosporangium aurantiacum IFO } \\
12592^{\mathrm{T}}\end{array}$ & 81 & 76 & 76 & 81 & 75 & 73 & 81 & 75 & 76 & 59 & 75 & & \\
\hline Micromonospora chalcea JCM $3031^{\mathrm{T}}$ & 67 & 74 & 67 & 61 & 61 & 56 & 78 & 78 & 79 & 53 & 83 & 71 & \\
\hline Nocardia asteroides JCM $3384^{\mathrm{T}}$ & 67 & 74 & 67 & 67 & 61 & 63 & 67 & 72 & 63 & 58 & 78 & 88 & 68 \\
\hline
\end{tabular}

${ }^{a}$ The SAS value for each pair of organisms for $20 \mathrm{~N}$-terminal amino acids of the AT-L30 protein was determined on the basis of the data shown in Fig. 1.

(ProBlott; Applied Biosystems, Foster City, Calif.), which was placed on the cathode side. The buffer solution used contained (per liter) $300 \mathrm{~g}$ of urea, $14 \mathrm{~g}$ of glycine, and $52 \mathrm{ml}$ of acetic acid (adjusted to $\mathrm{pH} 4.0$ with $5 \mathrm{~N} \mathrm{KOH}$ ). After blotting, the membrane was stained with a $0.2 \%$ solution of Coomassie blue, and then the spot identified as the AT-L30 protein was cut from the gel. Each spot contained 30 to 100 pmol of protein. The membrane piece with the spot was washed four times with $10 \mathrm{ml}$ of a $60 \%$ methanol solution containing $7 \%$ acetic acid. The washed piece was used for amino acid sequence analysis. An amino acid sequence analysis of each

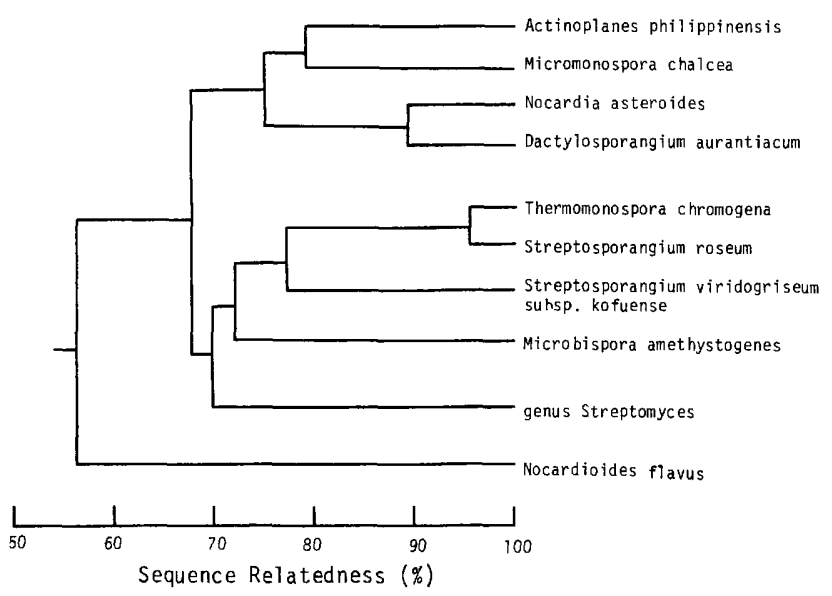

FIG. 2. Clustering based on AT-L30 protein SAS values. The dendrogram was drawn by using the data in Fig. 1 .
AT-L30 protein was performed by using a model $470 \mathrm{~A}$ protein sequencer (Applied Biosystems). The method which we used was based on the Edman degradation, and determination of a maximum of $25 \mathrm{~N}$-terminal amino acids was possible when about 100 pmol of AT-L30 preparation was used. In $E$. coli the L30 protein that corresponds to actinomycete AT-L.30 proteins consists of 58 amino acid residues. The $25 \mathrm{~N}$-terminal amino acids, therefore, represent nearly one-half of the whole AT$\mathrm{L} 30$ protein, assuming that the $\mathrm{L} 30$ protein from $E$. coli and the AT-L30 proteins from actinomycetes are the same size.

\section{RESULTS AND DISCUSSION}

Amino acid sequences of AT-L30 proteins. (i) Streptomyces. We first analyzed AT-L30 proteins from 22 strains of 12 species belonging to the genus Streptomyces, and from strains belonging to other representative actinomycete genera (Fig. 1). [Streptomyces coelicolor A3(2) has been shown to be a misclassified strain of Streptomyces violaceoruber (1, 13).] Figure 1 shows that we found high levels of amino acid sequence homology within the genus Streptomyces, while lower levels of homology were detected among the actinomycete genera. To express quantitatively the levels of similarity of the amino acid sequences (SAS values), we determined the frequency of appearance of the same amino acid in $20 \mathrm{~N}$-terminal amino acids of each AT-L30 protein. The SAS values determined in this way for combinations of representative strains are shown in Table 2. On the basis of the SAS values shown in Table 2, we drew dendrograms (Fig. 2 and 3). The trees were constructed by using a phylogenetic algorithm. The tree in Fig. 2 has three main branches; the first branch includes the genera Actinoplanes, Micromonospora, Nocardia, and Dactylosporangium, the second branch includes the genera Thermomonospora, Strep- 


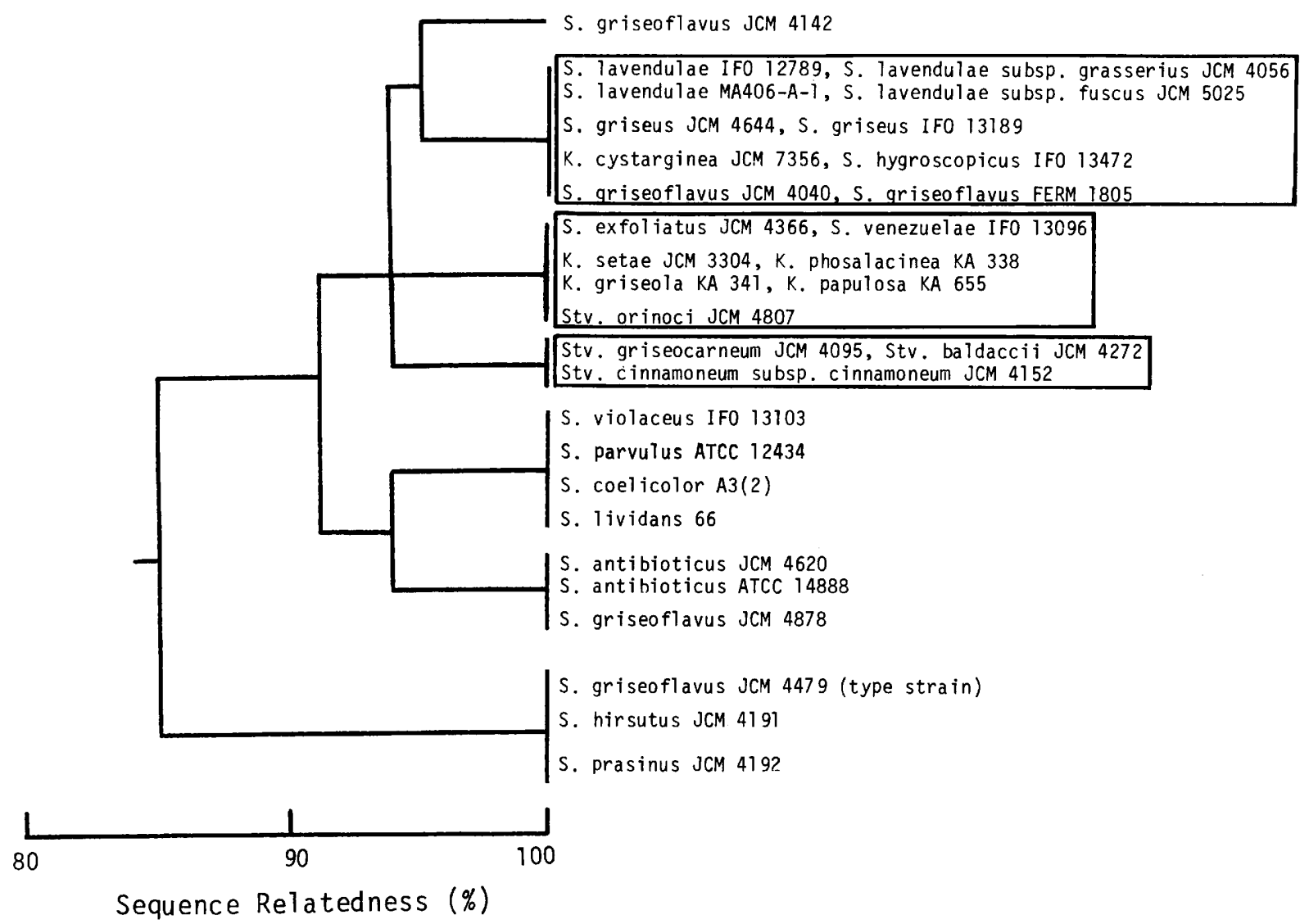

FIG. 3. Clustering based on AT-L30 protein SAS values. The dendrogram was drawn by using the data in Fig. 1, 4, and 5. S., Streptomyces; K., Kitasatosporia; Stv., Streptoverticillium.

tosporangium, Microbispora, and Streptomyces, and the third branch contains the genus Nocardioides. The greatest phylogenetic distances were between the genus Nocardioides and the other genera. In general, our classification was very similar to the classification of Stackebrandt and his colleagues (11, $28-30$ ), which was based on 16 S rRNA data. The results of Stackebrandt et al. are summarized and shown in a dendrogram in Bergey's Manual of Systematic Bacteriology (4). The only difference was that the genera Thermomonospora and Streptosporangium appeared to be closely related on the basis of our data, whereas those taxa were rather distantly related as determined by the 16S rRNA analysis (4).

The members of the genus Streptomyces examined exhibited high levels of homology (SAS values, 83 to $100 \%$ ) within the genus, and three main branches were identified (Fig. 3). The first branch included Streptomyces lavendulae, Streptomyces griseus, Streptomyces hygroscopicus, Streptomyces exfoliatus, and Streptomyces venezuelae. The second branch included Streptomyces violaceus, Streptomyces parvulus, Streptomyces coelicolor A3(2), Streptomyces lividans 66, and Streptomyces antibioticus. The third cluster, whose members appeared to be distantly related to the other taxa, included Streptomyces griseoflavus, Streptomyces hirsutus, and Streptomyces prasinus; the members of this cluster were characterized by arginine at position 4 (Fig. 1). There were many combinations which produced an SAS value of $100 \%$ and thus formed subclusters on the phylogenetic tree. As expected, in most cases strains classified in the same species exhibited $100 \%$ homology in their amino acid sequences; this was true for strains of Streptomyces lavendulae,
Streptomyces griseus, and Streptomyces antibioticus (Fig. 1 and 3). The exceptions were strains assigned to Streptomyces griseoflavus; four of the strains examined (JCM 4040, JCM 4142, JCM 4878, and FERM 1805) were classified in taxa different from the taxon that contained the type strain of Streptomyces griseoflavus, strain JCM 4479. In the light of the findings described above, these four strains were apparently misidentified as Streptomyces griseoflavus, unless variability in the amino acid sequence of the AT-L30 protein is a characteristic typical of this species. In particular, the N-terminal amino acid sequence (Met-Arg-Ile) found in strain JCM 4142 was peculiar since this sequence has not been found in the $\mathrm{N}$ terminus of any other actinomycete AT-L30 protein examined so far. This fact may imply that strain JCM 4142 should be classified in a new species or in a species which has not been subjected to AT-L30 analyses.

(ii) Streptoverticillium. Members of four species classified in the genus Streptoverticillium, including Streptoverticillium baldaccii JCM 4272 (the type strain of the type species), were subjected to an amino acid sequence analysis (Fig. 4). The four species exhibited high levels of homology (SAS values, 94 to $100 \%$ ) in comparisons with each other; $100 \%$ homology was detected among Streptoverticillium baldaccii, Streptoverticillium cinnamoneum subsp. cinnamoneum, and Streptoverticillium griseocarneum (Fig. 3). These organisms were most closely related to Streptomyces exfoliatus and were relatively closely related to Streptomyces lavendulae, but they were distantly related to Streptomyces violaceus, Streptomyces coelicolor A3(2), and Streptomyces antibioticus. Streptoverticillium orinoci 

1
5
10
15
20
1) Ala -Arg-Leu-Lys-Va T-Thr-Gln-Thr-Lys-Ser-Tyr-I1 e-Gl y-Ser-Lys-G1n-Asn- ? - ? -Asp-Thr-Leu
2) Ala -Arg-Leu-Lys-Val -Thr-Gin-Val-Lys-Ser Tyr-Il e-Gl y Ser Lys-Gin-Asn- ? - ? -Asp Thr Leu
3) Ala -Arg-Leu-Lys-Val-Thr-Gln-Val-Lys-Ser Tyr fIle-Gl y Ser LLys-Gin-Asn- ? - ? -Asp
5) Ala-Arg-Leu-Lys-Val-Thr-G1n-Thr-Lys-Ser Tyr-Ile-Gly Ser Lys-G1n-Asn- ? - ? -Asp Thr fLeu- ? -Ser-Leu

FIG. 4. Primary structures of N termini of AT-L30 proteins from several species of the genus Streptoverticillium. The amino acids that characterized the genus Streptomyces are boxed. Line 1, Streptomyces exfoliatus $\mathrm{JCM} 4366^{\mathrm{T}}$; line 2 , Streptoverticillium baldaccii $\mathrm{JCM} 4272^{\mathrm{T}}$; line 3 , Streptoverticillium griseocarneum JCM $4095^{\mathrm{T}}$; line 4, Streptoverticillium cinnamoneum subsp. cinnamoneum JCM 4152 ${ }^{\mathrm{T}}$; line 5 , Streptoverticillium orinoci JCM $4807^{\mathrm{T}}$.

exhibited $100 \%$ homology to Streptomyces exfoliatus. These results agree with the $16 \mathrm{~S}$ rRNA analysis results of Witt and Stackebrandt (36) and thus strongly support the suggestion of these authors that the genera Streptoverticillium and Streptomyces should be united.

(iii) Kitasatosporia. Members of five species classified in the genus Kitasatosporia, including $K$. setae JCM 3304 (the type strain of the type species), exhibited high levels of homology (SAS values, 94 to $100 \%$ ) in comparisons with each other (Fig. 5); $100 \%$ homology was detected among K. setae, Kitosatosporia papulosa, $K$. phosalacinea, and $K$. griseola. These four species exhibited $100 \%$ homology to Streptomyces exfoliatus and were closely related to Streptomyces lavendulae and streptoverticillia (SAS value, 94\%) (Fig. 3); similar conclusions were obtained from a 16S rRNA analysis (33). K. cystarginea exhibited $100 \%$ homology to Streptomyces lavendulae. These results clearly indicate that the members of the genus Kitasatosporia should be placed in the genus Streptomyces, as suggested by Wellington et al. (33).

Amino acid sequences characteristic of the genus Streptomyces. In addition to simple comparisons of the levels of homology of amino acid sequences, it was possible to pinpoint amino acids located at specific positions which characterize each genus. This has been done elsewhere for the genera Escherichia, Bacillus, Staphylococcus, Thermoactinomyces, and Thermomonospora (20a). The amino acid located at position 12 (position 11 in actinomycetes) was a particularly important signature amino acid for classification at the genus level. Furthermore, in the genus Streptomyces, position 11 was characterized by tyrosine (Fig. 1), which is an amino acid that has not been found in the other AT-L30 proteins examined so far. In other genera of actinomycetes, position 11 was occupied by lysine, serine, valine, leucine, glycine, threonine, or glutamic acid (Fig. 1). Thus, the occupation of position 11 by tyrosine appears to be a characteristic typical of the genus Streptomyces.
Also, serine at position 14 and threonine at position 21 are characteristic of this genus. It should also be noted that the strains classified in the genera Streptoverticillium and Kitasatosporia all had tyrosine, serine, and threonine at positions 11, 14, and 21, respectively (Fig. 4 and 5). Thus, the suggestion that these genera should be combined with the genus Streptomyces was supported by the amino acids that characterize each genus.

In this study, using our new approach, we confirmed the previous conclusions of Witt and Stackebrandt (36) and Wellington et al. (33), which were based on 16S rRNA analysis data. Thus, we reached the same conclusion that the genera Streptoverticillium and Kitasatosporia should be united with the genus Streptomyces. The agreement of phylogenetic relatedness data for various actinomycete genera obtained when our method (Fig. 2) and the 16S rRNA analysis method (4) were used is also notable. These facts, together with previous results (18-25), verify the efficacy of ribosomal protein AT-L30 analysis for identification and classification of actinomycetes.

Williams et al. (35) described phenetic classification of Streptomyces species; in their study, 394 type cultures of Streptomyces species were subjected to a numerical classification analysis based on 139 criteria. The findings of Williams et al. were consistent with our data in several respects. (i) Streptomyces hirsutus and Streptomyces prasinus, both of which were placed in Streptomyces griseoflavus cluster A37 of Williams et al., exhibited $100 \%$ sequence homology to the type strain of Streptomyces griseoflavus. (ii) Streptoverticillium cinnamoneum and Streptoverticillium griseocarneum, both of which were placed in Streptomyces cluster F55, exhibited $100 \%$ sequence homology to one another. (iii) Streptoverticillia (Streptoverticillium cinnamoneum, Streptoverticillium griseocarneum, Streptoverticillium baldaccii, and Streptoverticillium orinoci) which were classified in cluster F along with Streptomyces lavendulae all exhibited high levels of homology to Streptomyces lavendulae. However, a difference between the two studies

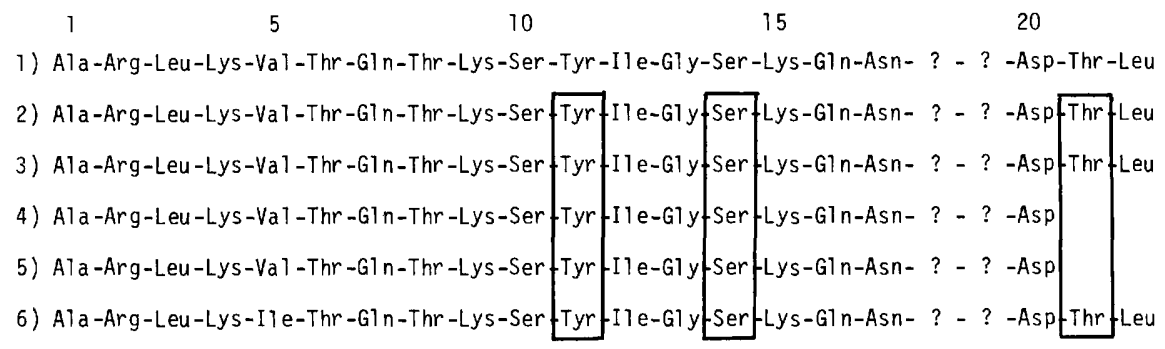

FIG. 5. Primary structures of N termini of AT-L30 proteins from several species of the genus Kitasatosporia. The amino acids that characterized the genus Streptomyces are boxed. Line 1, Streptomyces exfoliatus JCM $4366^{\mathrm{T}}$; line 2 , K. setae JCM $3304^{\mathrm{T}}$; line 3 , K. griseola KA $341^{\mathrm{T}}$; line 4 , K. phosalacinea KA $338^{\mathrm{T}}$; line $5, K$ papulosa KA $655^{\mathrm{T}}$; line $6, K$. cystarginea $\mathrm{JCM} 7356^{\mathrm{T}}$. 
was also found; although Streptomyces violaceus and Streptomyces venezuelae were both classified in cluster A6 of Williams et al., these species were placed in different clusters on the basis of our AT-L30 sequence analysis data. Drawing conclusions concerning species relationships might lead to overinterpretation of the data when highly conserved molecules, such as ribosomal proteins, are involved.

Streptomyces lavendulae occupies a rather distant taxonomic position (cluster group F) compared with other Streptomyces species in numerical classification systems (35). The 16S rRNA data also indicated that Streptomyces lavendulae should be separated from other streptomycetes and belongs in a subgroup that contains strains previously classified as members of the genus Streptoverticillium, indicating that Streptomyces lavendulae is more closely related to verticillium-bearing strains than to strains that produce straight or spiral chains (36). Despite the agreement of the phenetic and 16S rRNA data, our study revealed that Streptomyces lavendulae is more closely related to the members of cluster group A, such as Streptomyces griseus, than to streptoverticillia. No explanation can be offered at this time, but it does seem likely that in this case the true relationships are those that are based on $16 \mathrm{~S}$ rRNA analysis data, given the excellent agreement with the phenetic data. More work on Streptomyces AT-L30 analysis is clearly needed.

\section{ACKNOWLEDGMENTS}

This study was supported in part by a grant from the Basic Research Core System.

We thank Y. Takahashi for providing the Kitasatosporia strains.

\section{REFERENCES}

1. Baylis, H. A., and M. J. Bibb. 1988. Organization of the ribosomal RNA genes in Streptomyces coelicolor A3(2). Mol. Gen. Genet. 211:191-196.

2. Collins, M. D., T. Pirouz, M. Goodfellow, and D. E. Minnikin. 1977. Distribution of menaquinones in actinomycetes and corynebacteria. J. Gen. Microbiol. 100:221-230.

3. Glazebrook, M. A., J. L. Doull, C. Stuttard, and L. C. Vining. 1990. Sporulation of Streptomyces venezuelae in submerged culture. J. Gen. Microbiol. 136:581-588.

4. Goodfellow, M. 1989. Suprageneric classification of actinomycetes, p. 2333-2339. In S. T. Williams, M. E. Sharpe, and J. G. Holt (ed.), Bergey's manual of systematic bacteriology, vol. 4. The Williams \& Wilkins Co., Baltimore.

5. Goodfellow, M., S. T. Williams, and G. Alderson. 1986. Transfer of Actinosporangium violaceum Krasil'nikov and Yuan, Actinosporangium vitaminophilum Shomura et al. and Actinopycnidium caeruleum Krasil'nikov to the genus Streptomyces, with amended descriptions of the species. Syst. Appl. Microbiol. 8:61-64.

6. Goodfellow, M., S. T. Williams, and G. Alderson. 1986. Transfer of Chainia species to the genus Streptomyces with amended descriptions of the species. Syst. Appl. Microbiol. 8:55-60.

7. Goodfellow, M., S. T. Williams, and G. Alderson. 1986. Transfer of Elytrosporangium brasiliense Falcao de Morais et al., Microellobosporia cinerea Cross et al., Microellobosporia flavea Cross et al., Microellobosporia grisea (Konev et al.) Pridham and Microellobosporia violacea (Tsyganov et al.) Pridham to the genus Streptomyces with amended descriptions of the species. Syst. Appl. Microbiol. 8:48-54.

8. Goodfellow, M., S. T. Williams, and G. Alderson. 1986. Transfer of Kitasatoa purpurea Matsumae and Hata to the genus Streptomyces as Streptomyces purpureus comb. nov. Syst. Appl. Microbiol. 8:6566.

9. Hardy, S. J. S., C. G. Kurland, P. Voynow, and G. Mora. 1969. The ribosomal proteins of Escherichia coli. I. Purification of $30 \mathrm{~S}$ ribosomal proteins. Biochemistry 8:2897-2905.

10. Kaltschmidt, E., and H. G. Wittmann. 1970. Ribosomal proteins. VII. Two-dimensional polyacrylamide gel electrophoresis for fin- ger-printing of ribosomal proteins. Anal. Biochem. 36:401-412.

11. Kroppenstedt, R. M., E. Stackebrandt, and M. Goodfellow. 1990. Taxonomic revision of the actinomycete genera Actinomadura and Microtetraspora. Syst. Appl. Microbiol. 13:148-160.

12. Kusakabe, H., and K. Isono. 1988. Taxonomic studies on Kitasatosporia cystarginea sp. nov., which produces a new antifungal antibiotic, cystargin. J. Antibiot. 41:1758-1762.

13. Kutzner, H. J., and S. A. Waksman. 1959. Streptomyces coelicolor Müller and Streptomyces violaceoruber Waksman and Curtis, two distinctly different organisms. J. Bacteriol. 78:528-538.

14. Lechevalier, M. P., C. De Bievre, and H. A. Lechevalier. 1977. Chemotaxonomy of aerobic actinomycetes: phospholipid composition. Biochem. Syst. Ecol. 5:249-260.

15. Lechevalier, M. P., and H. A. Lechevalier. 1970. Chemical composition as a criterion in the classification of aerobic actinomycetes. Int. J. Syst. Bacteriol. 20:435-443.

16. Locci, R., and G. M. Schofield. 1989. Genus Streptoverticillium, p. 2492-2504. In S. T. Williams, M. E. Sharpe, and J. G. Holt (ed.), Bergey's manual of systematic bacteriology, vol. 4. The Williams \& Wilkins Co., Baltimore.

17. Nakagaito, Y., A. Shimazu, A. Yokota, and T. Hasegawa. 1992. Proposal of Streptomyces atroaurantiacus sp. nov. and Streptomyces kifunensis sp. nov. and transferring Kitasatosporia cystarginea Kusakabe and Isono to the genus Streptomyces as Streptomyces cystargineus comb. nov. J. Gen. Appl. Microbiol. 38:627-633.

18. Ochi, K. 1989. Heterogeneity of ribosomal proteins among Streptomyces species and its application to identification. J. Gen. Microbiol. 135:2635-2642.

19. Ochi, K. 1992. Electrophoretic heterogeneity of ribosomal protein AT-L30 among actinomycete genera. Int. J. Syst. Bacteriol. 42: 144-150.

20. Ochi, K. 1992. Polyacrylamide gel electrophoresis analysis of ribosomal protein: a new approach for actinomycete taxonomy. Gene 115:261-265.

20a.Ochi, K. Microbiology, in press.

21. Ochi, K., K. Haraguchi, and S. Miyadoh. 1993. A taxonomic review of the genus Microbispora by analysis of ribosomal protein AT-L30. Int. J. Syst. Bacteriol. 43:58-62.

22. Ochi, K., and S. Miyadoh. 1992. Polyacrylamide gel electrophoresis analysis of ribosomal protein AT-L30 from an actinomycete genus, Streptosporangium. Int. J. Syst. Bacteriol. 42:151-155.

23. Ochi, K., S. Miyadoh, and T. Tamura. 1991. Polyacrylamide gel electrophoresis analysis of ribosomal protein AT-L30 as a novel approach to actinomycete taxonomy: application to the genera Actinomadura and Microtetraspora. Int. J. Syst. Bacteriol. 41:234239

24. Ochi, K., E. Satoh, and J. Shima. 1993. Amino acid sequence analysis of ribosomal protein AT-L30 from Streptosporangium corrugatum and Kibdelosporangium aridum. Syst. Appl. Microbiol. 16:13-16.

25. Ochi, K., and M. Yoshida. 1991. Polyacrylamide gel electrophoresis analysis of mycolateless wall chemotype VI actinomycetes. Int. J. Syst. Bacteriol. 41:402-405.

26. Omura, S., Y. Takahashi, and Y. Iwai. 1989. Genus Kitasatosporia, p. 2594-2598. In S. T. Williams, M. E. Sharpe, and J. G. Holt (ed.), Bergey's manual of systematic bacteriology, vol. 4. The Williams \& Wilkins Co., Baltimore.

27. Omura, S., Y. Takahashi, Y. Iwai, and H. Tanaka. 1982. Kitasatosporia, a new genus of the order Actinomycetales. J. Antibiot. 35: 1013-1019.

28. Stackebrandt, E., W. Ludwig, E. Seewaldt, and K.-H. Schleifer. 1983. Phylogeny of sporeforming members of the order Actinomycetales. Int. J. Syst. Bacteriol. 33:173-180.

29. Stackebrandt, E., and C. R. Woese. 1981. Towards a phylogeny of the actinomycetes and related organisms. Curr. Microbiol. 4:197202.

30. Stackebrandt, E., B. Wunner-Füssl, V. J. Fowler, and K.-H. Schleifer. 1981. Deoxyribonucleic acid homologies and ribosomal ribonucleic acid similarities among sporeforming members of the order Actinomycetales. Int. J. Syst. Bacteriol. 31:420-431.

31. Takahashi, Y., Y. Iwai, and S. Omura. 1983. Relationship between cell morphology and the types of diaminopimelic acid in Kitasato- 
sporia cetae. J. Gen. Appl. Microbiol. 29:459-465.

32. Takahashi, Y., Y. Iwai, and S. Omura. 1984. Two new species of the genus Kitasatosporia, Kitasatosporia phosalacinea sp. nov. and Kitasatosporia griseola sp. nov. J. Gen. Appl. Microbiol. 30:377-387.

33. Wellington, E. M. H., E. Stackebrandt, D. Sanders, J. Wolstrup, and N. O. G. Jorgensen. 1992. Taxonomic status of Kitasatosporia and proposed unification with Streptomyces on the basis of phenotypic and 16S rRNA analysis and emendation of Streptomyces Waksman and Henrici 1943, 339 ${ }^{\mathrm{AL}}$. Int. J. Syst. Bacteriol. 42:156160 .
34. Wellington, E. M. H., and S. T. Williams. 1981. Host ranges of phage isolated to Streptomyces and other genera. Zentralbl. Bakteriol. Mikrobiol. Hyg. Abt. 1 11(Suppl.):93-98.

35. Williams, S. T., M. Goodfellow, G. Alderson, E. M. H. Wellington, P. H. A. Sneath, and M. J. Sackin. 1983. Numerical classification of Streptomyces and related genera. J. Gen. Microbiol. 129:1743-1813.

36. Witt, D., and E. Stackebrandt. 1990. Unification of the genera Streptoverticillium and Streptomyces, and amendation of Streptomyces Waksman and Henrici 1943, 339 $9^{\mathrm{AL}}$. Syst. Appl. Microbiol. 13:361-371. 